\title{
Sobre a natureza e a educação dos corpos na perspectiva anarquista da Escola Moderna de Barcelona ${ }^{1}$
}

\section{On nature and body education in the anarchist perspective of Escuela Moderna de Barcelona}

\author{
Pedro Henrique Prado da Silva* \\ Marcus Aurelio Taborda de Oliveira**
}

\begin{abstract}
RESUMO
O trabalho discute algumas prescrições e práticas para a educação dos corpos na experiência anarquista da Escola Moderna de Barcelona. Ancorados em um conjunto de reflexões sobre a natureza para o melhor desenvolvimento da educação, percorremos documentos que vão desde tratados sobre a natureza, livros didáticos e artigos publicados no Boletín de la Escuela Moderna no período entre a década de 80 do século XIX e a primeira década do séc. XX. Capturando a voga modernizadora da educação que, no entanto, recuperava a tradição para defender um "retorno à natureza", os anarquistas se mostraram sintonizados com os apelos do seu tempo, mas inovaram ao propor uma educação que questionava o status quo, o autoritarismo e advogava a emancipação dos trabalhadores. Para eles, educar era mais do que instruir. Assim, se eles também repercutiram essa preocupação com a regeneração do povo, a sua proposta assumia características particulares, no sentido de formar sujeitos capazes de lutarem por uma sociedade mais justa, livre e igualitária Por isso, atividades como passeios, excursões, além de práticas escolares nas quais a natureza fosse conhecida e compreendida,
\end{abstract}

1 Este trabalho é parte dos resultados do projeto Corpos, natureza e sensibilidades em perspectiva transnacional (entre as décadas finais do século XIX e a década de 1970), desenvolvido junto ao Núcleo de Pesquisas sobre a Educação dos Sentidos e das Sensibilidades - NUPES, na Universidade Federal de Minas Gerais, com financiamento do CNPq sob n. 409171/2018-2.

* Instituto Federal do Norte de Minas Gerais. Teófilo Otoni, Minas Gerais, Brasil. E-mail: profpedrohprado@gmail.com - https://orcid.org/0000-0002-0681-6591

** Universidade Federal de Minas Gerais/CNPq. Belo Horizonte, Minas Gerais, Brasil. E-mail: marcustaborda@uol.com.br - http://orcid.org/0000-0002-6079-9710 
eram atividades essenciais para que os alunos superassem o obscurantismo e a ignorância que ajudavam a fomentar todas as formas de dominação. Naquela experiência a educação dos corpos era fundamental.

Palavras-chave: História da educação. Educação do corpo. natureza e educação. Educação anarquista. Escola Moderna de Barcelona.

\begin{abstract}
The work discusses some prescriptions for the education of bodies in the anarchist experience of the Modern School of Barcelona. Anchored in a set of reflections on nature for the better development of education. We analyse different documents as a compendium of nature knowledge, textbooks, and articles published in Boletín de La Escuela Moderna in the period between the 1880s and the first decade of the 20th. century. Despite capturing the modernizing trend of education, it also recovered the tradition to defend a "return to nature". The anarchists showed themselves attuned to the appeals of their time, but innovated in proposing an education that questioned the status quo, authoritarianism, and advocated the worker's emancipation. For them, educating was more than instructing. For this reason, activities such as day-trips, travels, in addition to school practices in which nature was explored and understood, were essential for students to overcome obscurantism and ignorance that helped stimulate all forms of domination. In that experience, the education of bodies was fundamental.
\end{abstract}

Keywords: History of education. Body education. Nature and education. Anarchist education; Modern School of Barcelona.

\title{
Introdução
}

A possibilidade do retorno do homem à natureza foi uma ideia presente no imaginário de diversos reformadores educacionais ao longo do século XIX e no início do XX, recuperando marcas deixadas pela tradição. Mesmo que suas definições fossem difusas, a depender dos diferentes contextos, a natureza foi focada como ambiente a ser perseguido pelo homem e local adequado para a formação dos corpos das crianças. Ainda no século XVIII, muitos pensadores demonstraram uma inclinação "idílica" na busca de uma formação humana que estivesse em harmonia com a natureza. Nomes como o de Jean Jacques Rousseau (1712-1778) e John Locke (1632-1704), pensadores que ajudaram a fundar o liberalismo e, notadamente, se envolveram no debate educacional, recorreram à 
natureza para elaborar suas reflexões pedagógicas. Eles se tornariam referência para muitas das reflexões que marcariam o debate pedagógico ao longo do séc. XIX, foco deste trabalho.

Fiel ao fundo comum de uma época, a busca da reconciliação do homem com a natureza tornou-se um percurso também traçado por pensadores reformadores e socialistas, desde o início do século XIX. Entre as proposições idealistas e as críticas à vida moderna, esses pensadores procuravam depurar as mazelas dos avanços da industrialização, da superpopulação nas grandes metrópoles que tiveram como consequência o aumento de contágio por doenças, a carestia da vida, a fome, a pauperização das moradias - tudo isso fazendo parte de um momento no qual as principais afetadas eram as chamadas "classes" populares. Os contornos e a densidade daquelas críticas fornecem as premissas das suas concepções, nas quais a ida à natureza era entendida como a busca (ou reencontro) de uma essência natural que foi esquecida pela intensa civilização e urbanização das cidades, entendimento presente nas reflexões de socialistas utópicos como Fourier (1768-1830) e Saint Simon (1760-1825) (VIDAL, 2019)2.

Circunscrevendo os limites deste artigo ao contexto espanhol, observamos entre a segunda metade do século XIX e o início do XX, um significativo número de iniciativas intelectuais com ideias e propósitos semelhantes, tais como aquelas defendidas por Francisco Giner de los Ríos, Manoel Bartolomeu Cossío e Ricardo Rubio, intelectuais do movimento renovador educacional espanhol agrupados em torno da Institución Libre de Enseñanza. Cabe destacar, ainda, naquele contexto, as iniciativas católicas, como aquela das escolas jesuíticas, além das experiências das Escuelas del Ave María, endossadas pelo padre Andres Manjón (FRADES, 2016). Em Barcelona, destacam-se as experiências das Escolas Bosques de Montjuich (MARTÍNEZ, 2000) e a Escola Municipal Parch de Montijuich, que, segundo Torrebadella (2020, p. 15, tradução nossa), tinham como propósito solucionar os problemas higiênico-pedagógicos dos

2 "Natureza" está longe de ser um termo unívoco. Raymond Williams (1992) mapeou o desenvolvimento histórico do termo em língua inglesa mostrando como ele, de acordo com a época e o lugar, significou o "mundo físico", o ambiente externo à cultura, a paisagem, os fenômenos observáveis, os instintos etc. Na esteira do seu desenvolvimento, "naturalismo" também está longe de ser preciso. Isso explica a polissemia localizada nas nossas fontes, logo, no artigo. Por vezes pode ser entendido como um "aspecto", uma "dimensão" ou um "caráter". Como procuramos mostrar, uma educação naturalista se caracterizaria por um ideal que advogava formas educativas menos "artificiais", com ênfase sobre a experiência em detrimento das ideias, menos centradas nos professores, mais afeitas ao desenvolvimento espontâneo das faculdades dos alunos, desde que devidamente mobilizadas as ferramentas adequadas para este fim. Uma educação naturalista aproximaria os alunos daquilo que é essencial, fundamental na vida, segundo as premissas de muitos reformadores. Pode-se argumentar que o cientificismo e um ambiente de reflexão romântica ajudaram a disseminar aquele ideário. 
escolares, tendo como medidas apresentadas "A necessidade de respirar ar puro e exercitar o corpo em ambientes saudáveis". Por fim, é possível perceber esses aspectos naturalistas nas concepções de anarquistas que inspiraram a experiência da Escola Moderna de Barcelona ${ }^{3}$, homens proeminentes no campo da ciência e educação e que figuravam nas páginas do Boletin de la Escuela Moderna, como Élisée Reclus e Paul Robin. Das suas formulações nos ocupamos.

Consideramos que as prescrições e atividades para a educação dos corpos das crianças nas escolas, com o intuito de estimular o contato dos alunos com a natureza, são diversas, indo dos passeios e excursões, colônias de férias, saídas a parques e bosques, até visitas a Museus Naturais e laboratórios. As finalidades de suas prescrições e práticas também foram variadas: buscavam o vigor da saúde física e a robustez dos corpos com os banhos de mar e as vantagens de respirar o ar puro; a ocupação do tempo livre com jogos em parques e bosques, por mero divertimento, além da busca do conhecimento sobre a natureza - inclusive sobre a natureza humana - em passeios e excursões, onde se tratava de Geografia, Geologia, Biologia, Higiene, Fisiologia etc. (SOARES, 2003).

Para os fins deste artigo, elegemos como fontes primárias as edições de 1901 a 1904 do "Boletim da Escola Moderna" - "Boletin de la Escuela Moderna", órgão informativo da Escola Moderna de Barcelona, e o manual “A Escola Nova: rascunhos de uma educação fundada sobre as leis da evolução humana" - "L'École Nouvelle: esquisse d'une educatión basée sur les lois de l'évolution humaine" (1904), escrito por Jean François Elslander (1865-1948), utilizado como material de apoio e formação dos docentes da Escola Moderna. Neles são possíveis extrair algumas prescrições da diretora Clemence Jacquinet, além dos anarquistas já mencionados Élisée Reclus e Paul Robin, e a descrição de atividades direcionadas a uma dimensão naturalista para a formação dos

3 De modo a não comprometer a narrativa e o eixo argumentativo central do trabalho, deixamos como nota as principais pesquisas que concentram suas análises sobre a Escola Moderna de Barcelona. Destacamos, primeiramente, as obras de Pere Solà Gussynier (1978; 1980) pela relevância dessas obras no meio acadêmico e, notadamente, pelo pesquisador ser a principal referência no assunto. Além dessas, sugerimos a leitura dos trabalhos de Angel Cappelletti (2012), Nora Muro (2009) e a tese de doutorado de Pascual Vicente Velázquez (2008), uma vez que deles é possível depreender um panorama detalhado sobre a trajetória histórica da Escola Moderna e suas práticas escolares. Ademais, temos a obra escrita por seu fundador Francisco Ferrer y Guardia (2013) que, além de ser uma excelente fonte, é uma ótima referência para a compreensão dos propósitos e dos projetos que a Escola Moderna de Barcelona tinha como intenção concretizar. Todos esses trabalhos encontram-se em língua castelhana, para leitura de trabalhos em língua portuguesa, ver as pesquisas de Prado da Silva $(2015 ; 2016)$ e a tese de doutorado de Santos (2014). O primeiro trata da difusão da Escola Moderna pelo ocidente e a história de seu fundador Francisco Ferrer y Guardia. Já a tese de Santos aborda as ideias pedagógicas que circulavam pela Escola Moderna e o desenvolvimento de algumas práticas escolares, com o intuito de esclarecer sobre o seu ensino racionalista e estabelecer suas diferenças com a educação liberal daquele momento. 
corpos dos escolares. Através dessas fontes, atentos às referências bibliográficas que tratam sobre o tema, procuramos aprofundar o entendimento da relação entre natureza e educação dos corpos no âmbito do pensamento anarquista, com destaque a alguns dos fundamentos da Escola Moderna de Barcelona, fundada por Francisco Ferrer y Guardia, em 1901. O recuo temporal à década de 1880 deve-se ao fato de cotejarmos, sem pretensão de comparar, a experiência renovadora da Institución Libre de Enseñanza, que lançou na Espanha algumas das bases da educação naturalista com sua ênfase na educação dos corpos. Com isso queremos assinalar que a experiência da Escola Moderna de Barcelona bebia no fundo comum de uma época, embora na experiência anarquista a revolução fosse um objetivo explícito. Definindo-se como "Inimigo das desigualdades sociais”, dizia Ferrer y Guardia, “(...) não me limitarei a lamentar os seus efeitos, mas desejo combater as suas causas, seguro que agindo assim chegaremos positivamente à justiça, isso é, àquela desejada igualdade que inspira todo o furor revolucionário (FERRER Y GUARDIA, 2013, p. 37, tradução nossa).

Os acontecimentos do pós-guerra de 1898 e da escalada dos ideais regeneracionistas, movimento que inflamou as críticas na qual sustentavam a necessidade de restruturação econômica, política e cultural na Espanha de modo a alcançar os níveis de outros países europeus, motivou o aparecimento de diversas experiências escolares oferecendo os contornos de um projeto de sociedade: europeizar o povo e erguer uma nova Espanha (VIÑAO, 2004, p. 19-20). Os anarquistas da Escola Moderna de Barcelona também repercutiram essa preocupação com a regeneração do povo, contudo com características particulares, no sentido de formar sujeitos capazes de lutarem por uma sociedade mais justa, livre e igualitária. Assim anunciavam em seu programa: "A missão da Escola Moderna é fazer com que os meninos e as meninas, confiados a ela, se tornem pessoas educadas, verdadeiras, justas e livres de qualquer preconceito" (FERRER Y GUARDIA, 2013, p. 38, tradução nossa). Para isso a ciência e a natureza eram elementos fundamentais em sua educação: "Para isso, substituirá o estudo dogmático pelo estudo racional das ciências naturais" (FERRER Y GUARDIA, 2013, p. 38, tradução nossa).

\section{Um retorno à natureza? O lugar da educação dos corpos na Escola Moderna de Barcelona}

Preocupações de caráter naturalista estão presentes nas prescrições e práticas da Escola Moderna de Barcelona desde a sua inauguração. Naquele ato, Salas Ánton, médico que fazia parte da Junta Consultiva da Escola, anunciava brevemente o seu sistema educativo. 
Não aqui... em um espaço limitado por quatro paredes, mas em campo aberto, alternado por arvoredos, jardins, pomares, terrenos dedicados ao cultivo de cereais e caminhadas extensas, deveríamos nos reunir para realizar esse ato, pois somos seguidores desses grandes pedagogos naturalistas, que fizeram o ensino consistir no contato direto do aluno com a natureza (BOLETIN, 1901, p. 4, tradução nossa).

O médico reforçava que a educação dos alunos devia ocorrer em contato com os espaços tais como bosques, jardins e parques, inclusive aqueles presentes na cidade de Barcelona, que constituíam os locais apropriados para esse fim. A clausura das crianças na Escola deveria ser superada com o propósito de reconciliá-las com essa natureza esquecida - um breve mas importante momento de rompimento com a vida ordinária e civilizada -, na tentativa de estimular o "instinto natural" e a espontaneidade das crianças através do exercício da sua liberdade. A sua conquista era bem-vinda quando o homem dominava o conhecimento sobre a natureza. Por isso, a utilidade de aprender sobre a natureza era fundamental para a preservação da humanidade, a partir da sua dominação e transformação em prol dos interesses e necessidades do homem, algo muito em voga no séc. XIX.

Em prescrição realizada no Boletin pelo anarquista Élisée Reclus sobre o ensino de Geografia, o autor reforçava a necessidade da elaboração de um método eficiente para o aprendizado dos alunos. Desse modo, sugeria os passeios e as excursões como uma boa estratégia, e dava ênfase ao lema "Voltemos então à natureza!" (RECLUS, 1903, p. 65, tradução nossa). O geógrafo francês assegurava que, "para aprender, devemos antes compreender" (RECLUS, 1903, p. 65, tradução nossa) e, por isso, a necessidade da experimentação das crianças em contato com a natureza para dominar o conhecimento sobre ela.

Deve-se considerar que as excursões de caráter instrutivo foram bastante difundidas na Espanha, sobretudo nas experiências da Institución Libre de Enseñanza - ILE ${ }^{4}$. Sob a direção de Manoel Bartolomeo Cossío, as excursões

4 A referência à Institución Libre de Enseñanza não é casual, aqui. Tratou-se de uma experiência pioneira de renovação da educação espanhola já na década de 1870. Alguns dos pressupostos básicos da educação dos corpos estavam enraizados nas suas práticas: a educação física, os jogos, os passeios e excursões, a higiene, a educação estética. Os seus dirigentes miravam a experiência educacional da Inglaterra e da Alemanha, principalmente, articulando argumentos entre o cientificismo e um ambiente de reflexão romântica. Muitos dos seus pressupostos estão no horizonte de expectativas dos intelectuais que atuaram na Escola Moderna de Barcelona, ainda que os contornos ideológicos das duas iniciativas fossem distintos. Mas ambas enfrentaram a tradição e propuseram formas de renovação pedagógica que marcariam a experiência escolar na Espanha, em alguma medida, no mundo. 
da ILE tiveram a sua prática impulsionada. Segundo Mayor Mayor (2002) os seus objetivos eram muitos:

Se busca um modo de vida em contato com as contribuições e os ensinamentos que a natureza fornecia... Quanto ao exercício físico envolvido na própria excursão, foi adicionada a aquisição de noções de outras disciplinas de grande interesse para as crianças: agricultura, biologia, botânica, história, arte, geografia, etc. (MAYOR MAYOR, 2002, p. 220).

A prática das excursões tinha como finalidade proporcionar um aprendizado de caráter multidisciplinar para a criança, um momento em que ela pudesse adquirir um conhecimento científico por meio do contato direto com a natureza. Logo, o desenvolvimento dessas atividades tinha como objetivo capacitar a criança em relação às leis naturais, físicas, químicas, as ciências da agricultura e botânica, o conhecimento sobre relevos, terrenos, montanhas, rios e mares - tudo isso com o propósito de destacar o poder do homem e o seu controle sobre o mundo natural.

No título denominado "Contra la Naturaleza", o anarquista francês Paul Robin alinhava sua proposta à de Reclus no entendimento de que conhecer a natureza era importante para controlá-la. Esse controle da natureza apresentavase como ação notadamente primordial para a manutenção da sobrevivência da civilização, pois,

Em muitos casos, o homem conseguiu, com a força do trabalho, vencer a Natureza, preservar-se de sua influência perniciosa, tornar úteis os fenômenos originalmente maus ou indiferentes e melhorar imensamente seus benefícios (ROBIN, 1902, p. 68, tradução nossa).

Essa passagem torna-se emblemática, pois, além do fato de enaltecer o trabalho do homem como marca do progresso das civilizações e da conquista da liberdade e autonomia sobre as penitências causadas pela natureza, ela nos apresenta ainda um deslocamento do pensamento romântico que entendia a natureza como elemento bom, detentor de virtudes, generoso por excelência, chegando-se a crer que tudo que vinha da natureza seria bom e belo, como sugere Soares (2015, p. 152): “...a compreensão de uma natureza generosa, plena de virtudes e pronta para educar e curar resulta de certa nostalgia vivida por aqueles que povoam as cidades, suas privações e seus desafios". 
Todavia, aquela retórica da "natureza perversa" não ganharia peso nas prescrições e práticas da Escola Moderna de Barcelona. O que se observa é o estímulo a atividades em que se retorna à natureza para bem se aproveitar dos benefícios que ela tem a oferecer. Um desses benefícios seria a restauração da ligação do homem com o mundo natural, que teria sido esquecido pela civilização. Isso pode ser verificado na atividade de lição de coisas. Em um exemplo que se utilizava de um conto infantil, denominado "Lección de Historia Natural", era descrito o diálogo entre pai e filho sobre um passeio que a criança fizera ao zoológico. Indagado pelo pai sobre o que ele havia visto no zoológico, o filho responde: "Sim, eu vi muitos animais: galinhas de diferentes países, pavões com aquele lindo leque, cabras, carneiros, macacos... depois panteras, tigres, hienas, leões! Oh, feras terríveis!" (BOLETIN, 1903, p. 76, tradução nossa). Dado o aparente juízo de valor sobre os animais, considerada a "maldade" no imaginário da criança, pois os animais carnívoros comem outros animais para se alimentarem, o pai tenta desconstruir essa compreensão e justifica que os animais comem outros porque essa seria a sua natureza, eles se movem por instinto. Indo além nas explicações, o pai considerava que maus são os homens que matam não apenas para a sobrevivência, mas para a satisfação de seus prazeres e excessos.

Sim, os homens são maus, porque não se contentam como as panteras, as hienas, os tigres e os leões que somente matam para comer, mas (os homens) matam pelo prazer de matar, e na natureza são os únicos capazes de tamanha maldade...

Ele (o homem) acabou de comer, o que não o impediu de sair para o campo para matar perdizes, galinholas, rolas e todos os tipos de passarinhos que alegram a floresta e que você gosta tanto de ouvir quando andamos por ela... E vai matando por simples diversão, vê a um pássaro que voa, aponta, dispara, e aquele ser que, um momento antes, cheio de vida, cantou um hino à natureza, cai ferido pelo projétil daquele caçador que se diverte matando (BOLETIN, 1903, p. 76, tradução nossa).

A lição apresenta a natureza como algo bom, pois respeitaria os impulsos naturais dos seres vivos; os instintos elementares que se expressam nos animais seriam modos de sobrevivência. Para os homens aquele impulso fora esquecido (ou negligenciado), o que os lançava em uma busca incessante de conquista, de dominação. Corrompido pela civilização e pelos prazeres que o progresso the proporcionou, o homem não se preocuparia mais com seus instintos naturais, nem com seu desenvolvimento natural: estaria fascinado em perseguir suas satisfações através da simples subjugação da natureza. Imbuído nesse propósito, ele não 
desejaria apenas sua sobrevivência, mesmo que isso estivesse na contramão de uma harmonia entre ele e a natureza. Ainda sobre o conto, o pai reforçava que essa suposta maldade estaria presente, inclusive, nos momentos de ócio e de lazer do homem. "Sim, e para que você possa ver quão terrível crueldade (o homem) é capaz, considere que entre as diversões humanas de homens civilizados incluem a caça de pombos, as lutas de cães e galos e até touradas" (BOLETIN, 1903, p. 76, tradução nossa).

É justamente diante dessa perspectiva negativa sobre a atuação do homem em relação à natureza que as prescrições e práticas educativas tinham como propósito a "reconciliação do homem com a natureza" (TABORDA DE OLIVEIRA, 2012, p. 93). Sendo quase que uma conquista regenerativa e terapêutica, o contato com a natureza e o domínio sobre seu conhecimento tornavam-se uma obsessão pedagógica do período. O programa da Escola Moderna sobre "Ciências Naturais", apresentado pela diretora Clemence Jacquinet, anunciava claramente o quanto os conteúdos ensinados tinham como finalidade o conhecimento sobre o mundo natural, incluindo o homem, de maneira que se pudesse conservar sua autonomia e existência, e a harmonia que presidia a relação entre ambos. Aqueles conteúdos configuravam um amplo programa de educação do corpo:

Os alunos serão ensinados a conhecer seu próprio corpo e as regras básicas de higiene elementar que é indispensável praticar para a manutenção da saúde.

Primeiramente, o professor mostrará a estrutura do corpo humano: o esqueleto, depois os músculos, órgãos de movimento, fazendo entender que os ossos nem sempre têm a mesma rigidez, já que os ossos são completamente moles na criança e que não adquirem consistência até o término do crescimento, sendo de suma importância permanecer sempre em movimentos regulares para não alterar a forma dos ossos quando ainda mantêm a flexibilidade.

A deformação do esqueleto não é apenas uma desvantagem física, mas causa sérios distúrbios à saúde, forçando os órgãos internos a tomar uma posição anormal (JACQUINET, 1901b, p. 37, tradução nossa).

Conhecer o funcionamento da fisiologia humana serviria para a manutenção da saúde física do homem e de seu crescimento saudável, natural. Assim, a Escola Moderna mostrava-se comprometida com o intuito de prescrever uma educação do corpo que respeitasse os meios naturais de desenvolvimento das crianças. Eram estimuladas as atividades que proporcionavam o desenvolvimento 
completo e harmonioso da criança. "Os jogos, o trabalho, serão as razões naturais que vamos dar ao treinamento físico. (...) Afirma a compreensão de que nenhuma ginástica metódica, racional, pode substituir, do ponto de vista educacional, a ginástica natural dos jogos e do trabalho", alertava o naturalista francês J. F Elslander em seu manual (ELSLANDER, 1904, p. 196-197, tradução nossa). Como sugeria o autor, nenhuma ginástica metódica seria tão eficiente quanto a "ginástica natural" dos jogos e as atividades do trabalho, pois o seu pressuposto era que elas desenvolveriam todo o corpo da criança, não privilegiando segmentos ou partes isoladas. Criticando a ginástica metódica, completava: "esses movimentos regulados, necessariamente menos diversos do que aqueles resultantes de exercícios livres, não garantem uma distribuição igualitária da atividade entre todas as partes do corpo" (ELSLANDER, 1904, p. 197, tradução nossa).

Pode-se sustentar que essa posição se assemelha muito com a de Herbert Spencer (1888) quando ele sai em defesa dos jogos em detrimento da ginástica, uma vez que os primeiros fornecem uma quantidade adequada de exercício físico para todo o corpo da criança, além de serem o modo mais natural de desenvolver fisicamente o aluno.

Como o exercicio natural espontaneo foi prohibido, e reconhecidas como são as más consequencias da falta de exercicio, adoptou-se um systema de exercicios facticios -a gymnastica. Admittimos que a gymnastica é melhor do que a falta absoluta de exercício; mas contestamos que ella seja um substituto de igual valor aos jogos. ...Em primeiro lugar, aquelles movimentos musculares regrados são necessariamente menos variados do que aquelles que acompanham os divertimentos juvenis: não garantem uma distribuição de acção tão equitativa por todas as partes do corpo; d'onde resulta que o exercício, recahido sobre pontos especiaes, produz mais depressa o cansaço do que os jogos. (...)

Os exercícios formaes da gymnastica são preferíveis á falta de exercício estabelecendo, também, que elles podem ser usados com vantagem como auxilios suplementares; contestamos, todavia, que elles possam substituir os exercicios designados pela Natureza. Para as meninas, como para os rapazes, actividade dos jogos para que os nossos instinctos nos impellem é essencial ao bem-estar do corpo (SPENCER, 1888, p. 245-247).

Percebe-se que na anterior prescrição do Elslander havia uma busca pelo espontâneo, pelo impulsivo, pela experimentação da liberdade que não deveria jamais ter como preceito controlar o desenvolvimento natural da criança; 
concebia que o desenvolvimento da criança deve ser efetuado livremente. Essa experiência de liberdade, marca indelével no ideário anarquista, estende-se a outras atividades, também consideradas naturais, como a luta e a dança. Por meio delas, como salientava o autor, exercitam-se "todos os recursos necessários para os jogos espontâneos e agressivos que os jovens têm a paixão". Na sua prescrição "um exercício deve ser realizado em condições de harmonia e graça, a fim de ter um certo escopo" (ELSLANDER, 1904, p. 205, tradução nossa).

Elslander afirmava que, devido à reorganização social e à evolução tecnológica então experimentada, a sociedade perdera seu "instinto natural" e, por isso, também as suas capacidades físicas elementares. Recorrendo à tradição o autor aludia aos gregos para enfatizar uma sociedade que respeitava o desenvolvimento harmonioso do homem, principalmente o desenvolvimento físico. O jogo, a dança e as lutas, afirmava Elslander, que para os gregos eram a preparação para a vida, deviam ser considerados como exemplos a serem imitados, pois "eles obedeceram aos impulsos da vida natural, que tende apenas ao cumprimento de desejos saudáveis" (ELSLANDER, 1904, p. 207, tradução nossa). Por fim, o autor realiza uma síntese sobre suas considerações acerca de uma formação naturalista do corpo das crianças:

...é fácil encontrar os elementos de uma educação física completa na natureza e na vida e não é necessário recorrer a meios artificiais quando a criança, de todos os seus músculos, de todo o seu corpo, tende tão poderosamente ao seu completo desenvolvimento orgânico (ELSLANDER, 1904, p. 209, tradução nossa).

A vida natural era, reconhecidamente, o modelo a ser imitado, e para tal era necessário conhecê-la. Desse modo, a diretora Clement Jacquinet destacava a necessidade, também, de serem conhecidos os fenômenos e as leis naturais.

Para completar suas aulas sobre a natureza, o professor também ensinará a compreender os fenômenos geológicos atuais, a situação da terra no universo, os principais movimentos astronômicos, a formação da crosta terrestre, da atmosfera, das nuvens, a ação da água em estado de vapor, chuva e gelo; fenômenos internos: vulcões e terremotos; fenômenos atmosféricos: ventos, tempestades; ação da luz na vida (JACQUINET, 1901b, p. 37, tradução nossa). 
FIGURA 1 - SALA DE HISTÓRIA NATURAL DA ESCOLA MODERNA DE BARCELONA

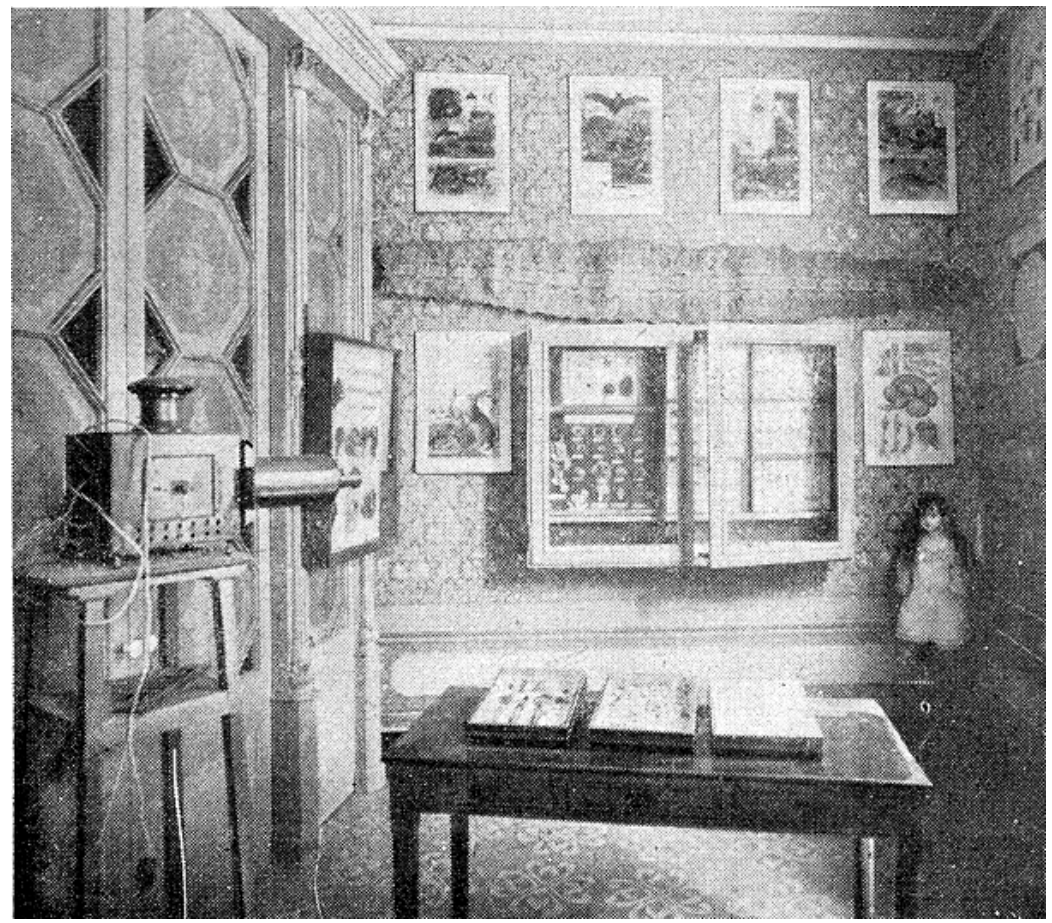

FONTE: Nuevo Mundo, 1907. Acervo Fundaciò Francisc Ferre i Guàrdia.

A imagem ilustra claramente que existe uma preocupação com a educação do corpo que se articula em torno do conhecimento sobre a natureza, ou o meio ambiente, e o homem. Naquela perspectiva, tratava-se de uma integração entre eles. Não é demais recordar sobre esse aspecto, que nos programas escolares desde o final do século XIX havia um forte apelo cientificista:

...não é de estranhar que parte da retórica sobre a natureza viesse ancorada em uma perspectiva de domínio e/ou apaziguamento daquelas forças que desafiavam a supremacia do homem, logo, da cultura. A apologia dos laboratórios, a História Natural, a Educação Física, a Higiene e os cuidados com o corpo (TABORDA DE OLIVEIRA, 2012, p. 94). 
Dessa forma, a ciência "positiva", coqueluche do período, foi incentivada e se manifestou nos programas escolares, com o propósito de fazer do conhecimento algo útil, no desejo de modelar e de transformar a natureza, portanto, o homem.

Contudo, nem sempre as estratégias para transmitir tais conhecimentos iam ao encontro daquilo que representaria a natureza - como os espaços ao ar livre, bosques, jardins e parques; muitas vezes, ela era trazida para a sala de aula, e o conhecimento era adaptado à realidade escolar por meio de livros didáticos, mapas, quadros, globo, equipamentos de laboratórios e, quando possível, visitas ao Museu Natural. "Vemos aqui o quanto esse retorno à natureza é racionalizado e adaptado às condições da vida social e urbana, metodicamente pensado e metodologicamente organizado" (SOARES, 2015, p. 155). Isso valia também para as concepções educativas defendidas por anarquistas e socialistas. O que diferenciava as suas perspectivas educativas daquelas tradicionais, como as católicas, e mesmo liberais, eram as finalidades do ensino, à quais estavam voltadas para a emancipação, a liberdade, e à crítica às formas arbitrárias de autoridade. Assim, como foi bastante difundido naquele período, em algumas atividades era necessário o auxílio de instalações e instrumentos para o aprofundamento dos estudos sobre o mundo natural. Como explicou a diretora da Escola Moderna, as aulas nas quais se apresentava a natureza de forma direta para os alunos, de modo que eles poderiam vê-la em toda sua concretude, eram as mais atrativas e despertavam um interesse maior.

No primeiro ano, começamos a familiarizar os alunos com o microscópio. Estudamos a germinação, observando vários grãos plantados para esse fim. E mais uma vez praticamente apreciamos a curiosidade efetiva que as crianças aplicam a esse trabalho, que é muito mais atrativo e proveitoso do que uma lição aprendida em um livro, por mais bem explicada e comentada que seja pelo professor (JACQUINET, 1902, p. 75, tradução nossa).

Em outras atividades, para a apreensão desse conhecimento útil, era necessário "instalar" os fenômenos naturais nos espaços escolares ou visitar outras instalações, como Museus de História Natural. Contudo, essas visitas deveriam ser orientadas e possuir uma sistematização programada de conteúdos a serem transmitidos aos alunos visitantes, não podendo ser caracterizadas como um simples passeio para ocupar o tempo livre. Como ressaltava Jacquinet, os alunos deviam encontrar nos museus

...verdadeiras ocasiões de aprender a ver e a acomparar, encontrando o complemento necessário das lições da sua clase, pois tudo que é explicado é aplicável, impulso aumentado ainda pelo vigor da sua idade, pelo fato de fazer visitas de surpresa à comunidade, tarde após tarde como uma simples distração (JACQUINET, 1903, p. 102, tradução nossa). 
Nessa linha de pensamento, como salientava a diretora, essas visitas, quando realizadas sem um objetivo claro, retiravam a possibilidade de os alunos observarem a beleza da natureza pela mobilização dos seus sentidos, pois

...o museu, que deveria contribuir para despertar sua própria originalidade, será horrível porque não lhes fará sentir as belezas naturais nem abordará sua sensibilidade, permanecerão inertes de inteligência diante das coleções silenciosas e misteriosas que, longe de ensinar a vida, não fazem mais que sentir a morte (JACQUINET, 1903, p. 102, tradução nossa).

No entendimento de Jacquinet os escolares deveriam apreender a "vida natural" tal como ocorreria a priori na natureza, nesse sentido era preciso animar essa sensibilidade das crianças nas visitas aos museus. Portanto, percebe-se que o estímulo por uma educação que propugnava o retorno à natureza também tinha entre as suas finalidades o desenvolvimento das sensibilidades dos alunos; por isso, a preocupação com os estudos sobre os "órgãos dos sentidos" (JACQUINET, 1901b, p. 37, tradução nossa). Pois é através dos sentidos que o homem toma contato com a natureza, e essa mesma natureza deveria ser observada com atenção para ser compreendida.

Em diferentes passagens no Boletin de la Escuela Moderna, está presente essa interação entre os sentidos corporais e o desenvolvimento das sensibilidades. Como explicava Reclus (1903) sobre os passeios e excursões para o ensino de Geografia: "Em vez de raciocinar sobre o inconcebível, comecemos a ver, observando e estudando o que está à nossa volta, ao alcance de nossos sentidos e de nossa experimentação" (RECLUS, 1903, p. 65, tradução nossa). Jacquinet, no entanto, salientava que era preciso buscar o conhecimento mais profundo da natureza por meio da visão, do olhar, da observação, fosse nas aulas de laboratório utilizando os microscópios, ou nas visitas aos Museus de História Natural. Para ela, "os museus de história natural visam instruir pela visão dos objetos, despertando a observação pessoal dos visitantes" (JACQUINET, 1903, p. 101, tradução nossa).

Estava na apuração dos sentidos dos alunos a janela que abriria novas sensibilidades decorrentes da observação desses fenômenos naturais; era na sua experimentação que se oportunizaria a aquisição do conhecimento, como também o despertar de afeições. 
A natureza perscrutada por todos os instrumentos da ciência deveria ser potencialmente transformada em objeto de conhecimento também no âmbito da educação, em especial da escolarização. Mas o maior instrumento para a sua exploração seria também "natural": os sentidos. A mobilização dos sentidos na busca da apreensão da "coisa natural" tinha como fulcro educar as formas de perceber e sentir a coisa, a natureza, a realidade. Tato, olfato, audição, paladar e visão (e para alguns, a percepção sinestésica), deveriam ser educados de forma a, em alguns casos, permitir a apropriação da natureza pelos alunos, de modo que pudessem desenvolver uma atitude de autonomia, pela via da experiência e do esclarecimento, em relação à cultura e à sociedade (TABORDA DE OLIVEIRA, 2012, p. 94).

Assim, educar os sentidos e a sensibilidade também fez parte do escopo educativo proposta da Escola Moderna em relação à educação do corpo. Era no domínio do mundo natural que se deveriam realizar os estudos que propiciariam a emancipação dos estudantes, projeto maior daquela concepção pedagógica.

Como exemplo podemos observar a excursão realizada pela Escola Moderna, liderada pelo geólogo Odon de Buen (colaborador da Escola e professor da Universidade de Barcelona), ao laboratório de Arago de BanyulsSur-Mer (França). São descritos no Boletin os impactos ocasionados pela viagem e pela contemplação da paisagem no percurso até o laboratório.

Acomodados no trem transbordando de alegria, partiram. Quando a luz do dia permitiu satisfazer o desejo vívido que sentiam os excursionistas, uma vez que a maioria deles nunca havia saído de Barcelona, (e estavam satisfeitos) de ver e receber novas impressões. Eles admiravam as belezas da paisagem, campos cultivados, florestas, fazendas, montanhas perdidas nas brumas do horizonte distante... tudo passou rapidamente diante dos olhos, produzindo sensações agradáveis e profundas (BOLETIN, 1904, p. 32, tradução nossa).

A riqueza dos detalhes mostrando como fora concebida a beleza da paisagem pelos alunos nos permite enfatizar que, para a Escola Moderna, esse retorno à natureza tinha como princípio a busca da bondade natural, da beleza verdadeira, que já existia na humanidade anteriormente, mas que fora desviada pelos aparatos civilizatórios e pelos grandes progressos da modernidade. Permanecem ecos românticos nessa idealização, mesmo que a ciência positiva fosse o mote daquelas prescrições. Mas não é demais recordar que mesmo aquela ciência propugnava a redenção do homem. 
FIGURA2 - RECORDAÇÃO DA EXCURSÃO CIENTÍFICAABANYULS-SUR-MER (FRANÇA), COM O GEÓLOGO ODON DE BUEN

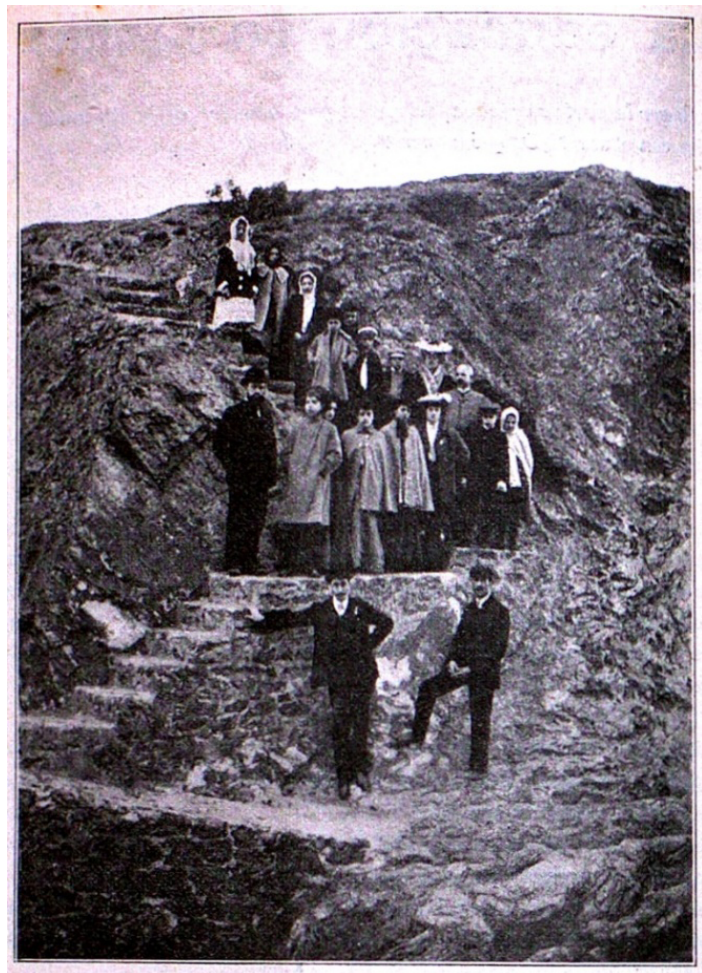

FONTE: Boletín de La Escuela Moderna, 1904. Acervo do International Institute of Social History, Amsterdã.

Essa outra imagem, ilustrativa, permite vislumbrar essa concepção de uma natureza boa, e de que tudo que dela provém seria algo bom e belo. Essa compreensão estava ancorada em uma dimensão moral que refletia, inclusive, na capacidade de organização e na disciplina dos alunos em sala de aula ou nas atividades fora do contexto escolar. Era entendido que o modo mais natural de os alunos se relacionarem entre si era aquele tal como a natureza se organizaria, na base da cooperação e da solidariedade. Fora disso, a competição e o egoísmo, por exemplo, seriam atitudes fomentadas pela civilização que corromperiam e não refletiriam a vontade natural dos alunos. Assim se exprimia a diretora da Escola Moderna de Barcelona, quando explicava sobre a disciplina na Escola e a atuação dos docentes para despertar esses "sentimentos naturais" nos alunos. 
Não é possível inspirar sentimentos elevados a todas as crianças e que elas se movam apenas sob o império de objetivos nobres, porque a maioria dos homens, grandes ou pequenos, é mais facilmente influenciado por seu interesse do que por suas ideias generosas. Por esse motivo, direcionamos nosso principal esforço para ensinar - o que é obviamente certo - que o interesse bem compreendido de cada um consiste no cumprimento de seu dever, que a felicidade de nossa vida está intimamente ligada ao nosso modo de entender e praticar a justiça, isto é, o bem...

A cada passo na vida, seja por nós mesmos ou por outros, podemos ver as consequências de nossas ações em relação à nossa vida atual e ao futuro da próxima geração. Todos os nossos cuidados devem, portanto, tender a nos ocupar com esta vida e torná-la cada vez mais de acordo a nossos fins naturais (JACQUINET, 1901a, p. 23-24, tradução nossa).

Jacquinet alegava que a natureza pode ser punitiva quando não se pratica essa "moral natural". Aludindo, ainda, à disciplina dos alunos, explicava que, quando um aluno preguiçoso não faz seus deveres e suas obrigações, acaba tendo que tomar mais tempo para finalizar suas tarefas, o que resultava em menos tempo para as brincadeiras.

...a pessoa preguiçosa é forçada a passar mais tempo trabalhando do que as outras, para compensar as horas perdidas, que não conseguiu gastar se divertindo, assim se castiga a si mesmo e se impõe uma tarefa maior para obter menos resultado do que se tivesse trabalhado bem desde o início. É o fundamento da lei natural que todos sofremos e que, sem graça ou perdão, pune inflexivelmente todos os nossos excessos (JACQUINET, 1901a, p. 23, tradução nossa).

Aparentemente, esse apego à natureza como detentora da verdade, promotora de uma beleza única, guia pelos caminhos certos e incorruptíveis, mas punitiva quando preciso, muito tem de uma ênfase quase religiosa. Faça-se apenas a substituição de Deus, o punitivo e vingativo, por Natureza - e teremos um emblema semelhante. Por isso, esclarece-nos Soares (2003, p. 24):

O domínio absoluto e violento do homem sobre o mundo natural lentamente cede espaço para outras compreensões e atitudes e uma devoção semi-religiosa perante a natureza selvagem instala-se, sobretudo, entre aqueles que não dependem ou não necessitam da terra para prover suas necessidades mais imediatas. Firma-se uma compreensão na qual a natureza é bela mas, sobretudo, benéfica, e exerce um saudável poder espiritual sobre o homem. 
Embora esse ethos seja manifesto e esteja nas ocorrências das práticas e prescrições da Escola Moderna, ele confronta com um marco particular da Escola que é o desejo claro de romper com as ideias cristãs e clericais da época. Quando anunciava as prescrições para o ensino de Geografia na Escola Moderna, Reclus destacava que a ciência moderna rompeu com o pensamento clerical, e isso se tornou o grande motor da mentalidade daquele momento. "Toda a história da ciência moderna, comparada com a escolástica da Idade Média, pode ser resumida em uma palavra: "de volta à natureza" (RECLUS, 1903, p. 65, tradução nossa).

A volta à natureza demonstrava que a verdade não estava mais nas forças divinas do cristianismo, traço bastante marcante na cultura ibérica. Não seria mais a vontade de Deus que moveria o homem, nem o conhecimento seria privilégio dos representantes da Igreja Católica. Pelo contrário, a verdade estaria na natureza: o homem moderno trataria das "coisas reais", e a única força que atuaria sobre ele seriam as leis naturais. Desse modo, era preciso buscar as respostas sobre a natureza nela mesma, para que se pudesse controlá-la, e assim conservar a autonomia e a liberdade humanas. A educação dos corpos era o vetor daquela finalidade pedagógica.

Quando recorremos ao programa da Escola Moderna, essa posição fica ainda mais explícita. Na já aludida inauguração da Escola, Salas Ánton explicava que as práticas do ensino naturalista seriam um modo de romper com os velhos dogmas do ensino clerical, que conduziam para "uma falsa interpretação dos sentidos": "Diferenciando-nos totalmente do sistema antigo e desacreditado, que consiste em encher a memória das crianças com letras mortas, regada pela autoridade tola do domínio, escravo submisso do dogma e daqueles que governam (BOLETIN, 1901, p. 4, tradução nossa).

Esse aspecto representa a posição particular da Escola Moderna em referência a um significativo movimento anticlerical, ancorado na tradição e no imobilismo do corpo e na prevalência da alma. Parece-nos que a Escola Moderna se embasava em uma educação naturalista para reforçar toda a capacidade da ciência de transformar a natureza, preservar a existência humana e sua autonomia; no entanto, faz, também, questão de marcar uma posição de deslocamento com as práticas cristãs da época. Não é um simples laicismo, é um combate às condutas e aos procedimentos da Igreja Católica na tentativa de demonstrar que a Escola Moderna se tornou uma alternativa antagônica àquela adquirida pela elite burguesa e cristã em Barcelona (e na Espanha), naquele momento. 


\section{Considerações finais}

A afirmação de uma via cujos contornos fazem apologia a uma educação naturalista do corpo, à busca de um instinto natural esquecido pelo homem, não significa que essas práticas visassem perseguir um modo mais elementar e primitivo de vida organizada. Sobre isso, é importante salientar, sobretudo quando o anarquismo se torna tendência ideológica da escola analisada, que nas prescrições e práticas da Escola Moderna não há alusão à busca por uma forma de organização social primitiva, por uma reintegração de um homem primitivo e não modernizado; ao contrário, como na retórica de outros pedagogos e reformadores da época, buscou-se uma adaptação e uma integração da realidade urbana e civilizada à natureza - por isso a difusão dos passeios campestres, idas aos bosques, jardins e parques, as visitas ao Museu de História Natural e aos laboratórios, aulas de higiene, jogos etc. Não estava no imaginário da Escola Moderna abdicar dos benefícios, as vantagens, o conforto e os prazeres que a vida moderna proporcionava, mas coadunar as duas possibilidades. Esse posicionamento da Escola Moderna pode nos dizer muito sobre o anarquismo quanto uma ideologia moderna que, longe de fugir da retórica do "progresso", "desenvolvimento" e "modernização", marca do ascenso reformador do século XIX e as primeiras décadas do XX, operava por subverter essa retórica em prol de um projeto de sociedade que garantisse os mesmos benefícios monopolizados por uma elite espanhola, às classes trabalhadoras e seus filhos. Isto é, a Escola Moderna não buscava uma sociedade primitiva/selvagem, mas a reconciliação do homem com a natureza sem perder do horizonte as promessas da era moderna: a prosperidade do povo por meio da ciência. A experiência espanhola revela como os anarquistas se utilizaram dessa concepção naturalista/científica a fim de politizar sua mobilização social de acordo com um projeto de sociedade a ser perseguido. Ao contrário de outras ideologias de corte liberal ou reacionário, que realizaram um movimento oposto, de despolitização e do uso dessa tendência para justificar as desigualdades sociais e a manutenção do poder de uma hegemonia elitista, com traços aristocráticos (SIERRA, 1996, 1999).

Por fim, essa proposta de educação do corpo na e pela natureza está ancorada também na estimulação dos sentidos e das sensibilidades das crianças. Era preciso desenvolver os órgãos sensitivos das crianças por meio das experiências que iriam adquirir em contato com o mundo circundante. Por isso se pode afirmar que essa via formativa tinha dois percursos: o primeiro, uma busca pela experimentação da natureza para a capacitação da criança em relação ao seu desenvolvimento e conhecimento. Através do contato com a natureza a criança 
deveria conhecê-la, reconhecendo-se naquele meio para dele melhor usufruir - eis a utilidade dessa experiência. O segundo está no desenvolvimento das sensações das crianças em contato com a natureza, uma nova sensibilidade. Contemplála seria um modo de desenvolver a fruição e resgatar sentimentos esquecidos pela vida urbana. Assim, tornam-se fundamentais, para o desenvolvimento da fruição nas crianças, as saídas a campo com o simples intuito de contemplar e observar a vida natural, vivificando a dimensão estética que o mundo natural conservaria. $\mathrm{O}$ desenvolvimento de práticas e prescrições que desenvolvessem os sentimentos de alegria e felicidade, as sensações de prazer nas atividades de contemplação da natureza, aliadas à utilidade do conhecimento sobre ela, eram objetivos perseguidos pela Escola Moderna de Barcelona. Daí a centralidade da educação dos corpos naquele projeto.

\section{REFERÊNCIAS}

BOLETIN DE LAESCUELA MODERNA. Inauguración de la Escuela Moderna. Boletin de la Escuela Moderna. Barcelona, Año I, nº 1, p. 4, 30 out. 1901.

BOLETIN DE LA ESCUELA MODERNA. Lección de Historia Natural. Boletin de la Escuela Moderna. Barcelona, Año II, nº 7, p. 76, 30 abr. 1903.

BOLETIN DE LA ESCUELA MODERNA. Excursión al laboratorio Arago de BanyulsSur-Mer. Boletin de la Escuela Moderna. Barcelona. Año IV, N 3, p. 32-33, 30 nov. 1904.

BOLETIN DE LA ESCUELA MODERNA. Recuerdo de la excursión á Banyuls-Sur-Mer. Boletin de la Escuela Moderna. Barcelona. Año IV, nº 4. p. 48, 31 dez. 1904.

CAPPELLETTI, Angel. Francisco Ferrer y La Pedagogia Libertária. Tenerife: Tierra de Fuego; Madrid: LaMalatesta Editorial, 2012.

ELSLANDER, Jean François. L'École Nouvelle: esquisse d'une educatión basée sur les lois de l'évolution humaine. Paris: J.Lebègue \& Ciè., 1904.

FERRER Y GUARDIA, Francisco. La Escuela Moderna. Madrid: LaMalatesta Editorial, 2013.

FRADES, Santiago Esteban. La renovación pedagógica en España: Un movimiento social más allá del didactismo. Tendencias Pedagógicas, Madrid, n. 27, p. 259-284, 2016.

JACQUINET, Clemence. Relación General. Boletin de la Escuela Moderna. Barcelona, Año I, no 2, p. 23-24, 30 nov. 1901a.

JACQUINET, Clemence. Ciencias Naturales. Boletin de la Escuela Moderna. Barcelona, Año I, no 3, p. 37-38, 31 dez. 1901b. 
JACQUINET, Clemence. Memoria de los estudios. Boletin de la Escuela Moderna. Barcelona, Año I, nº 6, p. 75, 30 abr. 1902.

JACQUINET, Clemence. Nuestros Museos de Historia Natural. Boletin de la Escuela Moderna. Barcelona, Año II, nº 9, p. 101-102, 30 jun. 1903.

MARTÍNEZ, Jose Mariano Brenal. De las escuelas al aire libre a las aulas de la naturaleza. Areas - Revista Internacional de Ciencias Sociales, Murcia, n. 20, p. 171-182, 2000.

MAYOR MAYOR, Alejandro. Historia de la Educación Física Infantil en España en el Siglo XIX. Universidad de Alcalá: Alcalá, 2002.

MURO, Nora. La Enseñanza en la Escuela Moderna de Francisco Ferrer y Guardia: Barcelona (1901-1906). Burgos: Editorial Gran Vía, 2009.

NUEVO MUNDO. Año XIV, nº 701. Madrid, 13 jun. 1907.

TABORDA DE OLIVERA, Marcus Aurélio. Em busca da natureza negada: a renovação pedagógica e o mito de uma educação "natural”. In: OLIVEIRA, Marcus Aurélio Taborda de (org.). Sentidos e Sensibilidades: sua Educação na História. Curitiba: Editora UFPR, 2012. p. 87-108.

PRADO DA SILVA, Pedro Henrique. Os germens são semeados: as experiências da Escola Moderna ao redor do mundo. Revista HISTED-BR Online, Campinas, n. 64, p. 201-220, 2015.

PRADO DA SILVA, Pedro Henrique. Francisco Ferrer y Guardia: um nome para a educação popular. Revista Educação Popular, Uberlândia, v. 15, n. 1, p. 10-25, jan./ jun. 2016.

RECLUS, Élisée, La Enseñanza de Geografía. Boletin de la Escuela Moderna. Barcelona, Año II, nº 6, p. 65-68, 1903.

ROBIN, Paul. Contra la Naturaleza. Boletin de la Escuela Moderna. Barcelona, Año II, No 6, p. 68-71, 30 abr. 1902.

SANTOS, Luciana Eliza dos. A educação libertária e o extraordinário: traços de uma pedagogia (r)evolucionária. 2014. 219f. Tese (Doutorado em Educação) - Universidade de São Paulo, São Paulo, 2014.

SIERRA, Álvaro Giron. Evolucionismo y anarquismo: la incorporación del vocabulario y los conceptos del evolucionismo biológico en el anarquismo español (1882-1914). Tesis (Doctorado en Historia). Madrid: Universidad Complutense de Madrid, Madrid, 1996.

SIERRA, Álvaro Giron. La economía moral de la naturaleza: darwinismo y lucha por la existencia en el anarquismo español (1882-1914). In: GLICK, Thomas F., RUIZ, Rosaura; SAMPER, Miguel Ángel Puig. El darwinismo en España e Iberoamérica. Madrid: Ediciones Doce Calles, 1999. p. 249- 263. Disponível em: http://hdl.handle. net/10261/47941. Acesso em: 02 set. 2020. 
SOARES, Carmen Lúcia. Georges Hébert e o Método Natural: nova sensibilidade, nova educação do corpo. Revista Brasileira de Ciências do Esporte, Brasília, v. 25, n. 1, p. 21-39, 2003.

SOARES, Carmen Lúcia. Uma educação pela natureza: o método de educação física de Georges Hébert. Revista Brasileira de Ciências do Esporte, Brasília, n. 37, v. 2, p. 151-157, 2015.

SOLÀ I GUSSINYER, Pere. Ferrer i Guardia i L'Escola Moderna. Barcelona: Curial, 1978.

SOLÀ I GUSSINYER, Pere. Educacion i Moviment Llibertari a Catalunya (1901-1939). Barcelona: Edicions 62, 1980.

SPENCER, Herbert. Educação Intellectual, moral e physica. Porto: Casa Editora Alcino Aranha \& Companhia, 1888.

TORREBADELLA, Xavier. La escolarización de la educación física: un análisis de cinco imágenes publicadas en la prensa de Barcelona de principios del siglo XX (1910-1913). Revista Brasileira de História da Educação, Maringá, v. 20, p. 1-30, 2020.

VELÁZQUEZ VICENTE, Pascual. La Escuela Moderna: una editorial y sus libros de texto (1901-1920). Tesis (Doctorado en Educación) - Faculdad de Educación, Universidad de Murcia, Múrcia, 2008.

VIDAL, Laurent. Eles sonharam um outro mundo. São Paulo: EDUSP, 2019.

VIÑAO, Antônio. Escuela paro todos: educación y modernidad en la España del siglo $X X$. Madrid: Marcial Pons Historia, 2004.

WILLIAMS, Raymond. Palavras-chave: um vocabulário de cultura e sociedade. São Paulo: Boitempo, 2007.

Texto recebido em 25/09/2020.

Texto aprovado em 25/01/2021. 